\title{
Conditional Cash Transfer Program Effects on Anthropometric Index from Children in Latin America: A Systematic Review
}

\author{
Larissa Grace Nogueira Serafim de Melo1 ${ }^{*}$, Severina Alice da Costa Uchoa ${ }^{2}$, \\ Ricardo Ney Oliveira Cobucci ${ }^{3}$, José Vilton Costa ${ }^{4}$, \\ Antonio José do Nascimento Gouveia Costa ${ }^{5}$, Isabella Tarciana Pinheiro de Gois ${ }^{5}$, \\ Mirella Cristina Silveira Gomes ${ }^{5}$ \\ ${ }^{1}$ Faculdade de Ciências da Saúde do Trairi, Universidade Federal do Rio Grande do Norte, Santa Cruz, Brasil \\ ${ }^{2}$ Departamento de Saúde Coletiva, Universidade Federal do Rio Grande do Norte, Natal, Brasil \\ ${ }^{3}$ Maternidade Escola Januário Cicco, Universidade Federal do Rio Grande do Norte, Natal, Brasil \\ ${ }^{4}$ Programa de Pós-Graduação em Demografia, Universidade Federal do Rio Grande do Norte, Natal, Brasil \\ ${ }^{5}$ Curso de Graduação em Medicina, Universidade Federal do Rio Grande do Norte, Natal, Brasil \\ Email: *larissagrace.nutricionista@gmail.com, alicedacostauchoa@gmail.com,drcobucci@gmail.com, \\ josevilton@gmail.com, antoniojesepc@gmail.com, isabellatarcianaufrn@gmail.com, \\ mirellacristinasg@gmail.com
}

Received 27 September 2015; accepted 23 May 2016; published 26 May 2016

Copyright (C) 2016 by authors and Scientific Research Publishing Inc.

This work is licensed under the Creative Commons Attribution International License (CC BY). http://creativecommons.org/licenses/by/4.0/

c) (i) Open Access

\section{Abstract}

Introduction: To compare the Brazilian conditional cash transfer program, the "Bolsa Família" with the similar programs found in Latin America regarding its effects in the children's growth and development. Methods: The systematic review contemplated the Scopus, Embase, Pubmed, Scielo and Lilacs data bases. The inclusion criteria were epidemiological quantitative, observational, descriptive and analytical studies that had as target public children contemplated by the income transfer program with health conditionalities in Latin America. Narrative reviews related to the research theme were excluded as well as systematic reviews with or without meta-analysis related to the research theme. Results: The titles and abridgements review from 1007 articles resulted in the selection of 17 complete studies. After the quality analysis of these, as well as the application of the inclusion criteria, 10 articles were included in this review. Among the types of epidemiologic studies selected to compose this systematic review, 3 are cohort analytical studies. Conclusion: Studies carried out in Brazil, Mexico, Ecuador and Nicaragua were selected and indicated the positive effects that the conditional income transfer brought to the anthropometric index from beneficiary children in the researched countries.

${ }^{*}$ Corresponding author. 


\section{Keywords}

\section{Cash Transfer Program, Child Development, Income Distribution, Primary Health Care}

\section{Introduction}

Currently in different countries, due to the labor crisis, social disadvantages accumulation and the fragilities of public protection systems, there is a special highlight to the designing and implementation of conditional cash transfer programs [1].

These programs consist in monetary transfers of financial resources, straight from the government, with no previous contribution, to families that have per capita income below the poverty line. In return, families make specific commitments related their children education and health [2].

In Latin America, although there are differences between the programs, such as access conditionals, benefit amount and management, there are, at least, three aspects that are common among those implemented in this region: the focus on families in social vulnerability situation (poor or in extreme poverty), with children and teenagers (except for the Uruguayan program), the conditionality principle and the non belonging to the permanent rights. Its main objective is to reduce infant mortality in children under the age of 5 caused by poverty related diseases that surpass generations such as malnutrition, diarrhea and respiratory infections [2] [3].

As a consequence of the spreading of these conditional cash transfer programs, common to several developing countries in different parts of the world, with a special highlight to Latin America, and in it Brazil, there is great international interest in getting to know the different effects of this policy, health effects inclusive. In this field, Lagarde, Haines and Palmer [4] made an important systematic review approaching the effects of conditional cash transfer in the improvement of the beneficiaries health, in developing countries, including Latin America. The results suggest that the conditional cash transfer programs are effective in the increasing of the use of primary attention to health services and, at times, in the improvement of its target public health.

In Brazil, a study made points that the "Bolsa Família" reduced $19.4 \%$ the general mortality among children in cities where there was a high coverage of the primary health care. This reduction was even bigger when the study considered specific mortality caused by some diseases such as malnutrition (65\%) and diarrhea (53\%). The Program "Saúde da Família" (PSF) also contributed to the mortality reduction in children under the age of 5 in a synergic effect with the program "Bolsa Família" [2].

Although there is some accumulation of evaluations regarding the impact on the cash transfer programs beneficiaries health, particularly in the infant growth and development, which is intimately related to the reduction of both diseases and death in childhood, there still is a shortage of more systematic evaluations about its evidences.

In this perspective, this review study objective is to compare the Brazilian conditional cash transfer program, the "Bolsa Família" with the other similar programs found in Latin America as to its effects in the children growing and development.

It has as a focus the anthropometric evaluation as one of the main components to children's growth and development. The anthropometric indicators are considered as of mere reference, and have advantages such as low cost, application and standardization ease, amplitude of the analyzed aspects, besides not depending on invasive proceedings, being the most adequate and viable technique to be adopted in health services [5].

\section{Methods}

It is a systematic review study made in the period of 2000 through 2012. The selection of studies was made between January and June of 2013 in the Scopus, Embase, Pubmed, Scielo and Lilacs data bases. The search was made without language restriction, through strategies that combined descriptors registered in the DECS (Descritoresem Ciências da Saúde) list, as described in Table 1.

The inclusion criteria used were the following:

- Epidemiologic quantitative, observational, descriptive and analytical studies that have as target public children benefited by the cash transfer programs with health conditionalities;

- Studies made with the cash transfer beneficiary population in 19 countries located in Latin America (Argentina, Brazil, Chile, Colombia, Costa Rica, Ecuador, El Salvador, Guatemala, Honduras, Jamaica, Mexico, 
Nicaragua, Panama, Paraguay, Peru, Dominican Republic, Trinidad and Tobago and Uruguay);

- The excluding criteria used were the following:

- Narrative reviews related to the research theme;

- Systematic reviews with or without meta-analysis related to the research theme.

The potentially relevant publications were selected through the analysis of both title and abridgement of the articles found in all the bases. The complete articles selected after the title and abridgement analysis were reviewed independently by the authors and included in the review according to the inclusion criteria. They were included in this review Observational Studies in Epidemiology. So the quality of the studies was assessed though the MOOSE strategy [6] (Figure 1).

After the study selection, there were made searches in the bibliographic references from this systematic review selected studies, not being found potentially relevant studies to be included in this paper.

Since this is a systematic review study, which uses secondary data, there was no need of an ethics committee approval.

\section{Results}

The titles and abridgements review of 1007 articles resulted in the selection of 17 complete studies. After the analysis of the quality of these, as well as the application of the inclusion criteria, 10 articles were included in this review Table 2.

\section{Discussion}

According to the results of this systematic review, it's possible to say that the conditional cash transfer brought positive effects in the anthropometric index of beneficiary children in the researched countries. Nevertheless, not all beneficiary children had their growth and development improved. Similar results were commonly observed in the evaluation of the effects of these same programs in the other Latin American countries included in this paper. The analysis of the of the results by age subsets was made in some of the evaluated studies. It's important to emphasize that the subset of children under 24 months seemed to have obtained better effects in the anthropometric index in most of the studies carried out in Brazil. The positive effect of the conditional cash transfer programs for this age range does not corroborate with one of the Brazilian studies, that stratify the results by age range, and revealed better effects of the program in children older than 12 months old.

Table 1. Terms used in these archstrategies of this systematic review.

\begin{tabular}{|c|c|c|}
\hline Potuguese & English & Spanish \\
\hline Indicadores de qualidade & Quality indicators & Indicadores de calidad \\
\hline Desenvolvimento infantile & Child development & Desarrolloinfantile \\
\hline Desnutrição infantile & Child malnutrition & Transtornos de lanutricióndelniño \\
\hline Distribuição de renda & Income distribution & Distribución de renta \\
\hline Transferência & Transfer & Distribución \\
\hline Renda & Income & Renta \\
\hline Programas de nutrição & Nutrition programs & Programas de nutrición \\
\hline Políticas públicas & Public policies & Políticas públicas \\
\hline Políticas sociais & Social policies & Políticas social \\
\hline Proteção social & Social protection & Política social \\
\hline Pobreza & Poverty & Pobreza \\
\hline Saúde infantil & Child health & Saluddelniño \\
\hline Cuidados primários em saúde & Primary healthcare & Atención primaria de salud \\
\hline Aleitamento materno & Breast feeding & Lactancia materna \\
\hline Mortalidade infantil & Child mortality & Mortalidad materna \\
\hline
\end{tabular}




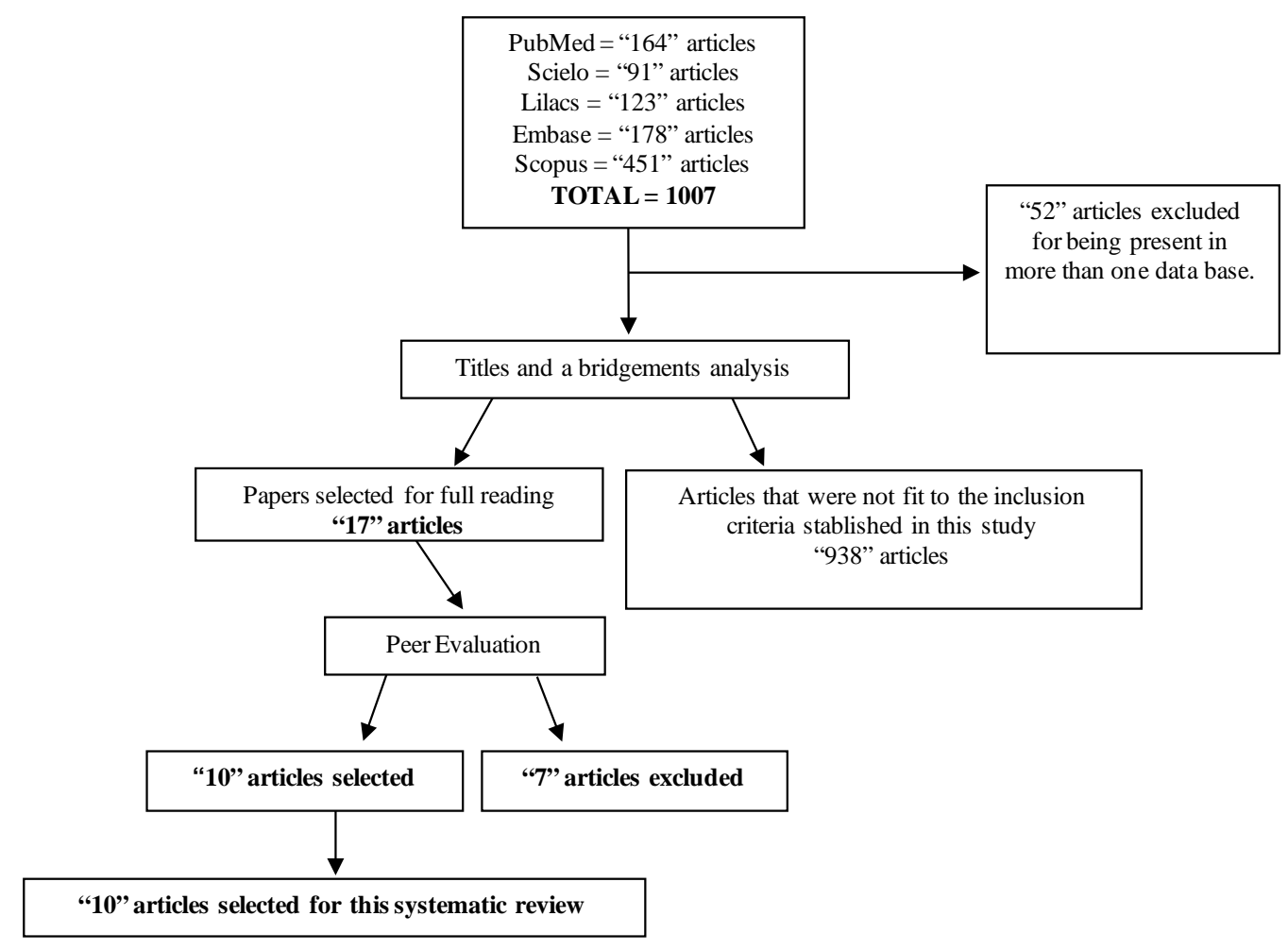

Figure 1. Flow diagram of the studies selection.

Positive effects in the anthropometric index of children benefited by cash transfer programs implemented in Latin America were also observed in systematic review made by Souza [17], that evaluated programs implemented in the following countries: Mexico, Nicaragua, Colombia, Ecuador and Brazil; and Lagarde, Haines and Palmer [4], that evaluated programs implemented in already mentioned countries and Ecuador.

Differently from the Brazilian cash transfer program, the Mexican program, besides the monetary benefit, offers nutritional supplements to children. The results found in the studies carried out by Rivera et al. [16], Fernald, Gertler and Neufeld [7] and Fernald, Gertler and Neufeld [8] showed improvement in the height-for-age index (H/A), and less prevalence of malnutrition among beneficiary Mexican children. Although in the Brazilian program (Bolsa Família) there is no use of nutritional supplement, the founds made by the index H/A evaluation, in the national studies of Paes-sousa, Santos and Miazaki [13] and Paula et al. [14] and are similar to the ones evidenced in the Mexican studies. The improvement in the anthropometric index and chronic malnutrition index reduction among children benefited by conditional cash transfer programs is also shown in a study carried out in Nicaragua, with results found by Macours, Schady and Vakis [11].

The high risk of overweight among Brazilian children benefited by the Bolsa Família program may be a demonstration that although the financial offer may guarantee bigger spending of families with food, it is likely that this allocation alone may not guarantee adequate eating habits to the beneficiary. According to Peixoto et al. [18], that carried out qualitative research with the objective of investigating meanings of the Bolsa Família program to beneficiary residents in a medium size city, located in the Brazilian northeast, observed an increase in family spending with food; in contrast, no positive effect in the nutritional state was observed, due to the diet quality.

The diet quality is directly associated with eating choices, that in turn have several determining factors. According to Lignani and Salles-Costa [19], that concluded studies with beneficiary families by the Bolsa Família program, it is needed to comprehend the beneficiary eating choices not only in the economy rationality and health perspective, once these families face several questions when purchasing food, such as: wide offer and reduced price of low nutritional value and high energy density, the publicity and merchandise of unhealthy food and the symbolic value of food as a consumption product. Thus, they suggest that the cash transfer programs must incorporate policies to facilitate healthy eating choices, starting with comprehensive public policies. 


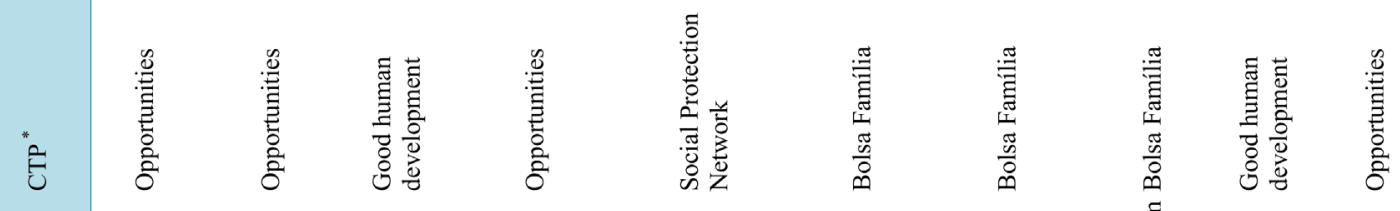

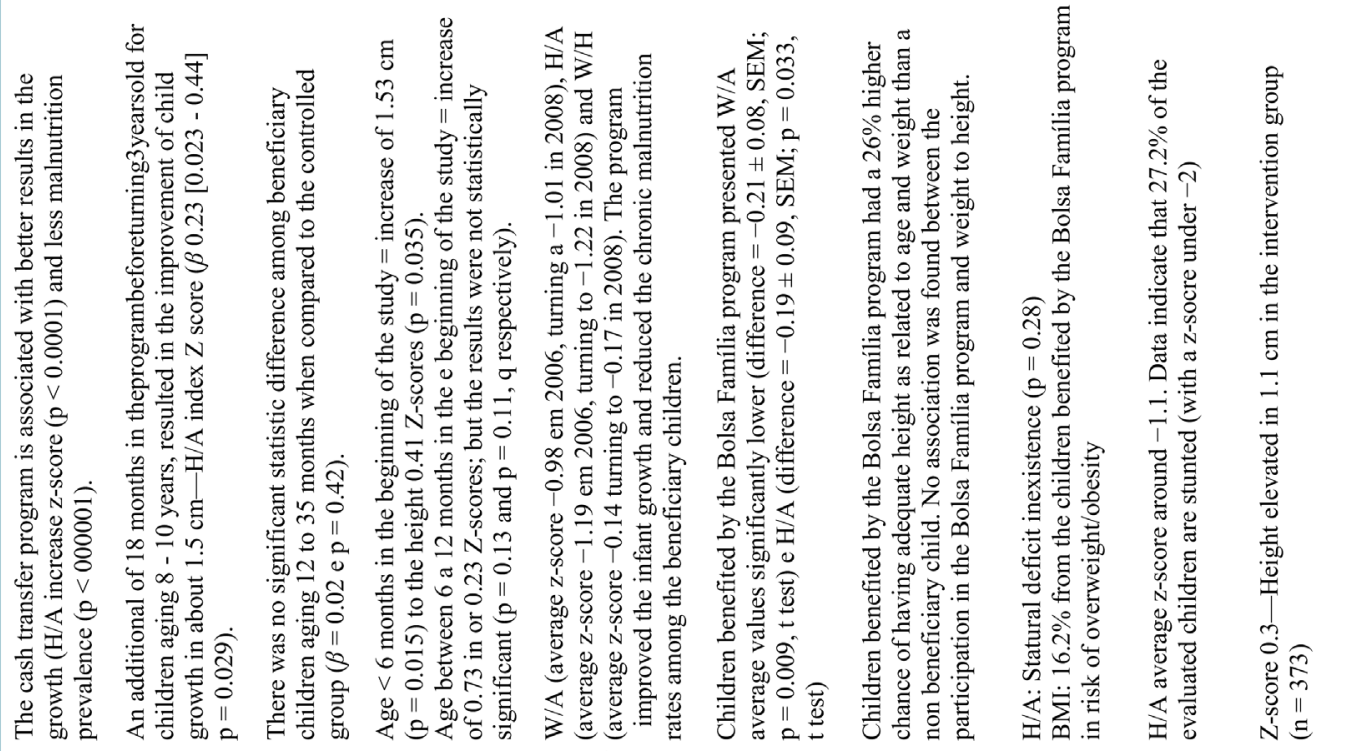
商 离

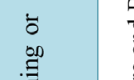

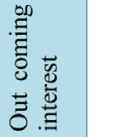

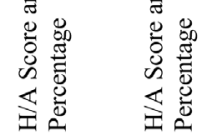

薄

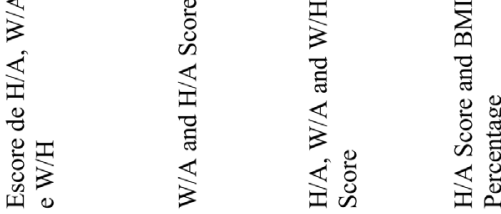

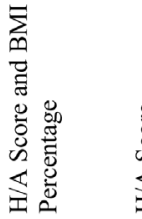

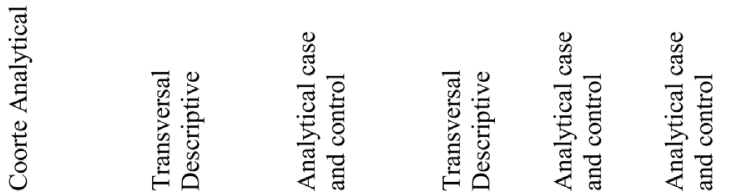

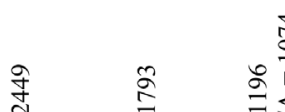

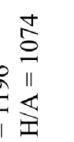

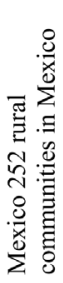

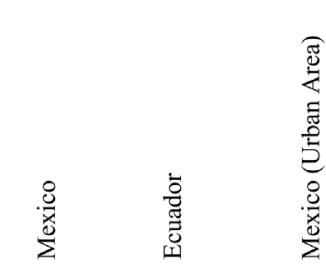

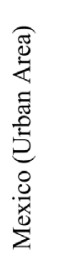

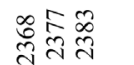

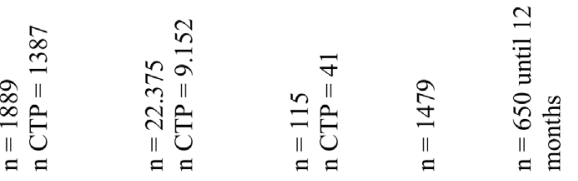

惫

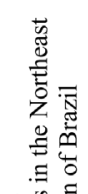

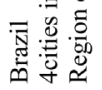

离

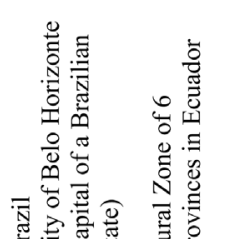

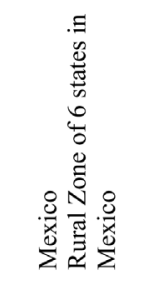


The retrospective cohort studies carried out by Morris et al. [12] found results that diverge from the other Brazilian studies included in this review, once they do not reveal meaningful evidence from positive effects in the anthropometric index of beneficiary children, when compared to non beneficiary. On the other hand, the results found in this study point average weight-for-age (W/A) and H/A values lower among beneficiary children. According the authors, this negative effect, unexpected for the Brazilian program, may be explained by the fact that those responsible for the children interpret wrongly the program eligibility rules, understanding that only children with under weight and/or height would be benefited. In fact, the Bolsa Família program does not take the nutritional state of the child as an inclusion criteria, but the family income.

The Brazilian studies carried out by Paula et al. [14], Paes-sousa, Santos and Miazaki [13] and Morris et al. [12] do not evidence important stature deficits among children benefited by conditional cash transfer. Thus, according to data from this systematic review, the Bolsa Família program is associated with better growth index for children. Similar result was observed in Mexico by Rivera et al. [16] and Leroy et al. [10], from the data analysis that associate the conditional cash transfer program with better $\mathrm{H} / \mathrm{A}$ index, specially evidenced among poorer children, and less than 12 or 24 months old.

The positive effect of the conditional cash transfer in lower income children growth was also found by Paxson and Schady [15] in Ecuador, once that evaluating children from lower social groups included in the program, found improvement in the anthropometric index that reflect in the growth and height for the age, in comparison with the control group. According to Souza [17], the efficiency of interevenction of conditional cash transfer evaluated in his research, seems to be directly proportional to the capacity of directing the program to families with very low income levels, once this measure may increase the capacity of inclusion of malnourished children in the program. It may be said that this fact was also evidenced in this systematic review.

Particularly, the results obtained by Macours, Schady and Vakis [11], seem to indicate that positive changes occurred in families behavior assisted by some conditionality cash transfer programs, underlining that these changes continued even after the end of the program duration, even though the studies findings do not leave clear if these changes were themselves responsible by the good results in the evaluated children's growth. It is important to underline that these same authors evidenced, among beneficiary families, an increase in the usage of services related to preventive health care directed to children. Evaluating this same aspect, the study carried out by Fernald and Hidrobo [9], related that the effect of the conditional cash transfer program implemented in Ecuador in the $\mathrm{Z}$ score $\mathrm{H} / \mathrm{A}$ index was considered meaningful for children whose mothers believed that receiving the program benefits depended solely on the fact of using the primary health care for their children's assistance.

According to Souza [17], the cash transfer programs with health conditionalities offer in an effective way the increasing of access to health services, as well as the utilization of health preventive measures, in specific contexts. Thus, the good results of cash transfer programs depend on the existence of good primary attention to health services, accessible to beneficiary families.

\section{Conclusions}

The results from the evaluated studies are usually similar, and indicate the positive effects that the conditional cash transfer brought to anthropometric index of beneficiary children in the researched countries. However, not all the beneficiary children improved their growth and development. The analysis of the age subgroups results was carried out in some of the evaluated studies. It is important to highlight that the 24 months old children subgroup seem to obtain better effects in the anthropometric index in most of the studies. In Brazil, children aged more than 12 months seem to be more benefited by the cash transfer program Bolsa Família.

The methodological limitations of the studies, the existence of other factors that may influence in the growth and development of children and the heterogeneity of both programs and populations researched, prevent our conclusion that the effect of anthropometric index is statistically meaningful. Thus, new studies with a more adequate methodology that may allow the carrying out of a meta-analysis are necessary to prove the positive effect in anthropometric index of children registered in conditional cash transfer program.

\section{Competing Interests}

The authors declare that they have no competing interests. 


\section{References}

[1] Magalhães, R., Burlandy, L. and Senna, M.C.M. (2012) Poverty, Social Inequalities and Health: Challenges for Public Policies. Rio de Janeiro, 12. http://www.scielo.br/pdf/csc/v12n6/v12n6a01.pdf

[2] Rasella, D., Aquino, R., Santos, C.A., Paes-Sousa, R. and Barreto, M.L. (2013) Effect of a Conditional Cash Transfer Programme on Childhood Mortality: A Nationwide Analysis of Brazilian Municipalities. Lancet, 382, 57-64. http://dx.doi.org/10.1016/S0140-6736(13)60715-1

[3] Fonseca, A.M.M. and Viana, A.L.D. (2007) Healthcare Rights and Conditional Cash Transfers in Latin America. Ciência \& Saúde Coletiva, 6, 1505-1512. http://www.scielosp.org/pdf/csc/v12n6/v12n6a10.pdf http://dx.doi.org/10.1590/S1413-81232007000600012

[4] Lagarde, M., Haines, A. and Palmer, N. (2007) Conditional Cash Transfers for Improving Uptake of Health Interventions in Low- and Middle-Income Countries: A Systematic Review. JAMA, 298, 1900-1910.

http://jama.jamanetwork.com/article.aspx?articleid=209295 http://dx.doi.org/10.1001/jama.298.16.1900

[5] Sigulem, D.M., Devincenzi, M.U. and Lessa, A.C. (2000) Diagnosis of Child and Adolescente Nutritional Status. Jornal de Pediatria (Rio J), 76, S275-S284. http://dx.doi.org/10.2223/JPED.164

[6] Stroup, D.F., Berlin, J.A., Morton, S.C., Olkin, I., Williamson, G.D., Rennie, D., Moher, D., Becker, B.J., Sipe, T.A. and Thacker, S.B. (2000) Meta-Analysis of Observational Studies in Epidemiology: A Proposal for Reporting. JAMA, 283, 2008-2012. http://dx.doi.org/10.1001/jama.283.15.2008

[7] Fernald, L.C.H., Gertler, P.J. and Neufeld, L.M. (2008) Role of Cash in Conditional Cash Transfer Programmes for Child Health, Growth, and Development: An Analysis of Mexico's Oportunidades. Lancet, 371, 828-837. http://www.thelancet.com/journals/lancet/article/PIIS0140-6736(08)60382-7/fulltext http://dx.doi.org/10.1016/S0140-6736(08)60382-7

[8] Fernauld, L.C.H., Gertler, P.J. and Neufeld, L.M. (2009) 10-Year Effect of Oportunidades, Mexico’s Conditional Cash Transfer Programme, on Child Growth, Cognition, Language, and Behaviour: A Longitudinal Follow-Up Study. Lancet, 374, 1997-2005.

http://www.thelancet.com/journals/lancet/article/PIIS0140-6736(09)61676-7/fulltext\#article_upsell http://dx.doi.org/10.1016/S0140-6736(09)61676-7

[9] Fernald, L.C.H. and Hidrobo, M. (2011) Effect of Ecuador's Cash Transfer Program (Bono de Desarrollo Humano) on Child Development in Infants and Toddlers: A Randomized Effectiveness Trial. Social Science \& Medicine, 72, 14371446. http://www.sciencedirect.com/science/article/pii/S0277953611001481 http://dx.doi.org/10.1016/j.socscimed.2011.03.005

[10] Leroy, J.L., García-Guerra, A., García, R., Dominguez, C., Rivera, J. and Neufeld, L.M. (2008) The Oportunidades Program Increases the Linear Growth of Children Enrolled at Young Ages in Urban Mexico. Journal of Nutrition, 138, 793-798. http://jn.nutrition.org/content/138/4/793.long

[11] Macours, K., Schady, N. and Vakis, R. (2012) Cash Transfers, Behavioral Changes, and Cognitive Development in Early Childhood: Evidence from a Randomized Experiment. American Economic Journal: Applied Economics, 4, 247273. http://www.aeaweb.org/articles.php?doi=10.1257/app.4.2.247 http://dx.doi.org/10.1257/app.4.2.247

[12] Morris, S.S., Olinto, P., Flores, R., Nilson, E.A. and Figueiró, A.C. (2004) Conditional Cash Transfers Are Associated with a Small Reduction in the Rate of Weight Gain of Preschool Children in Northeast Brazil. Journal of Nutrition, 134, 2336-2341. http://jn.nutrition.org/content/134/9/2336.long

[13] Paes-Sousa, R., Santos, L.M. and Miazaki, É.S. (2011) Effects of a Conditional Cash Transfer Programme on Child Nutrition in Brazil. Bulletin of the World Health Organization, 89, 496-503. http://dx.doi.org/10.2471/BLT.10.084202

[14] Paula, D.V., Botelho, L.P., Zanirati, V.F., Lopes, A.C.S. and Santos, L.C. (2012) Nutritional Assessment and Standard of Food Consumption among Benefitial and Non-Beneficial Children of Transfer Program Incomes, in a School of the Municipality of Belo Horizonte, State of Minas Gerais, Brazil, in 2009. Epidemiologia e Serviços de Saúde, 21, 385394. http://dx.doi.org/10.5123/S1679-49742012000300004

[15] Paxson, C. and Schady, N. (2010) Does Money Matter? The Effects of Cash Transfers on Child Development in Rural Ecuador. Economic Development and Cultural Change, 59, 187-229. http://dx.doi.org/10.1086/655458

[16] Rivera, J.A., Sotres-Alvarez, D., Habicht, J.P., Shamah, T. and Villalpando, S. (2004) Impact of the Mexican Program for Education, Health, and Nutrition (Progresa) on Rates of Growth and Anemia in Infants and Young Children: A Randomized Effectiveness Study. JAMA, 291, 2563-2570. http://dx.doi.org/10.1001/jama.291.21.2563

[17] de Souza, A.L.M. (2009) Conditional Cash Transfer Programs and Their Impact on the Nutritional Status of Children and Adults in the Northeast of Brazil [tese]. Nutrição Humana Aplicada, São Paulo.

[18] Peixoto, J.B.S., Silva, V.C., Paiva, A.A. and Gama, J.S.F.A. (2011) Meaning of Conditionalities of the Family Grant 
Program for Beneficiaries Accompanied in the Family Health Strategy in Campina Grande-PB. Revista Brasileira de Ciências da Saúde, 15, 129-136. http://dx.doi.org/10.4034/RBCS/2011.15.02.02

[19] Lignani, J.B. and Salles-Costa, R. (2008) Participation of the Bolsa Família Program in the Changes of Food Consumption Families Benefited from the Program. http://www.ipc-undp.org/publications/mds/28P.pdf

\author{
Abbreviations List \\ PSF: Programa Saúde da Família \\ Embase: Excerpta Medicadata BASE \\ Scielo: Scientific Electronic Library Online \\ Lilacs: Literatura Latino-Americana e do Caribe em Ciências da Saúde \\ DECS: Descritores em Ciências da Saúde \\ H/A: Height-for-Age \\ W/A: Weight-for-Age
}

